\title{
Direct Quantitative Bisulfite Sequencing Using Tag-modified Primers and Internal Normalization
}

\author{
DIMO DIETRICH ${ }^{1,2}$ \\ ${ }^{1}$ Institute of Pathology, University Hospital Bonn, Bonn, Germany; \\ ${ }^{2}$ Department of Otolaryngology, Head and Neck Surgery, University Hospital Bonn, Bonn, Germany
}

\begin{abstract}
For the investigation of DNA methylation patterns, bisulfite conversion of the DNA followed by polymerase chain reaction $(P C R)$ amplification and sequencing of the region of interest is the method of choice when information at single CpG site resolution is desired. In this study, a simple method for direct quantitative bisulfite sequencing based on the Sanger method is shown to be usable for the accurate analysis of single CpG sites. This method is based on the usage of tagmodified primers to obtain an internal normalization signal within the PCR product.
\end{abstract}

DNA methylation alterations are among the most promising candidates for cancer biomarker research. Sequencing of bisulfite DNA is the preferred method when detailed information on the methylation pattern of a given template is desired at single $\mathrm{CpG}$ resolution. Currently, bisulfite sequencing based on the chain-termination reaction developed by Sanger and co-workers is among the most commonly used methods for methylation analysis $(1,2)$. Quantification of methylation is usually carried out by cloning of the polymerase chain reaction (PCR) product followed by sequencing a number of individual clones. Therefore, the resolution directly correlates with the number of analyzed clones, which is time consuming and expensive when a high resolution is desired. A more cost-efficient and faster approach is achieved by direct sequencing of the PCR product without any cloning steps (3). This approach provides a quantitative measure of the degree of methylation at a particular target site by comparing cytosine and thymine signals. However, it is susceptible to basecaller artefacts and therefore limited in its resolution. Other technologies, such

Correspondence to: Dimo Dietrich, University Hospital Bonn, Department of Otolaryngology, Head and Neck Surgery, SigmundFreud-Str. 25, 53127 Bonn, Germany. Tel: +49 22828715173, Fax: +49 22828715030, e-mail: dimo.dietrich@gmail.com

Key Words: DNA methylation, direct quantitative bisulfite sequencing, internal normalization, Sanger method. as pyrosequencing $(4,5)$, also allow for the quantitative analysis of single $\mathrm{CpG}$ sites, but the required instruments are less commonly available in many laboratories.

Thus, inexpensive and simple methods for the accurate quantification of single $\mathrm{CpG}$ sites with direct bisulfite sequencing using standard laboratory equipment, such as capillary electrophoresis instruments, would offer a significant improvement for DNA methylation analysis.

Here, an improved method for quantitative bisulfite sequencing of single $\mathrm{CpG}$ sites based on the Sanger method is presented. Accurate quantification is achieved by the incorporation of a domain into the PCR product, which is subsequently used for signal normalization (6).

\section{Materials and Methods}

Unmethylated DNA was prepared by multiple displacement amplification (MDA), a genome-wide amplification method (7). For the preparation of DNA mixtures with defined methylation ratios, a portion of the MDA amplificate was treated with SssI methyltransferase (New England Biolabs, Ipswich, MA, USA) in the presence of S-adenosyl-methionine, according to the manufacturer's instructions, and mixed with the unmethylated amplificate to give mixtures representing $0,5,10,15,25,50,75$ and $100 \%$ methylation. Two micrograms of each of these mixtures were bisulfite treated using the EpiTect ${ }^{\circledR}$ kit (Qiagen, Hilden, Germany). The resulting bisulfite DNA concentration was determined by UV spectrophotometry using a Nanodrop ${ }^{\circledR}$ ND-1000 spectral photometer (Nanodrop Technologies, Wilmington, DE, USA).

PCR amplification was carried out at $25 \mu \mathrm{l}$ scale (10 ng DNA, 1 U HotStar Taq polymerase (Qiagen), 1 x PCR buffer (Qiagen), 0.2 $\mathrm{mM}$ each dNTP (Fermentas, Burlington, Canada), $0.5 \mu \mathrm{M}$ both primers (reverse primer: aggtgTTCTAATCCTCCTTTCCACAATAA, forward primer: GTAGGGGAGGGAAGTAGATGTT; the normalization domain is indicated using lower case letters). Incubation was performed using the following temperature profile: $15 \mathrm{~min}$ at $95^{\circ} \mathrm{C}$ and 45 cycles with $20 \mathrm{~s}$ at $95^{\circ} \mathrm{C}, 45 \mathrm{~s}$ at $58^{\circ} \mathrm{C}$ and 30 $\mathrm{s}$ at $72^{\circ} \mathrm{C}$. Sequencing was carried as previously described (6). Raw data were extracted from the $\mathrm{ABI}$ sequencing electropherograms using BioEdit 6.0.7 software (Isis Pharmaceuticals, Inc., Carlsbad, CA, USA). The trace containing the methylation information was visualized and the normalization signal identified. Electropherograms were aligned using the normalization signals in the primer tails. The 


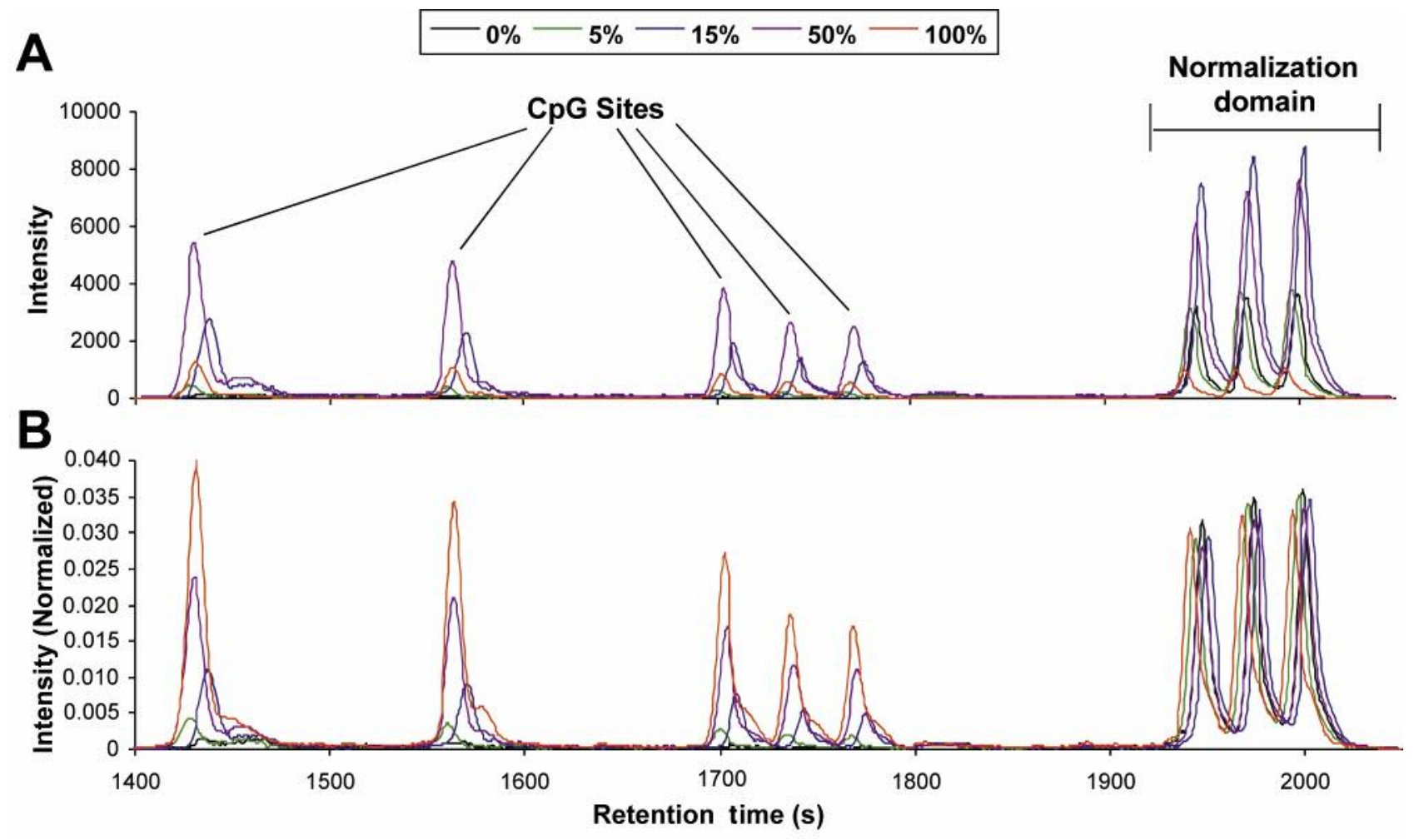

Figure 1. Principle of signal normalization. Sequence electropherograms (cytosine traces only) from five mixtures of methylated and unmethylated DNA $(0,5,15,50$, and 100\% methylated DNA) before $(A)$ and after $(B)$ signal normalization. Normalization is achieved by dividing the intensity by the area of the normalization signal.

signals were normalized by integrating the signals of the normalization domain and by dividing each data point of the electropherogram by this reference value. Thirty data points surrounding each identified peak maximum within each trace were integrated to obtain the methylation score for the respective $\mathrm{CpG}$.

\section{Results}

The principle of the signal normalization is shown in Figure 1. The cytosine traces containing the methylation information from five different methylated DNA mixtures are shown before (Figure 1A) and after normalization (Figure 1B). The normalization signal was derived from the three cytosines, which were incorporated into the PCR product. After normalization, the peak areas (and heights) at the $\mathrm{CpG}$ sites of interest were found to correlate with the relative methylation of the template DNA.

The methylation of five single $\mathrm{CpG}$ sites within the promoter region of the PITX2 gene was analyzed in order to demonstrate the power of the direct quantitative bisulfite sequencing method. For this purpose, DNA mixtures of unmethylated and methylated DNA were prepared and analyzed. The paired-like homeodomain 2 (PITX2) gene was chosen since it represents one of the best validated DNA methylaion biomarkers in various types of cancer $(8-11,13$, 14). The results of the analysis of five $\mathrm{CpG}$ sites within the PITX2 gene are illustrated in Figure 2. The areas of the normalized methylation signals correlated well with the methylation of the applied DNA mixture for each of the five CpG sites (Figure 2). All seven mixtures (0, 5, 10, 25, 50, 75 and $100 \%$ ) were clearly distinguishable.

\section{Discussion}

DNA methylation biomarkers have shown promising results in the clinical management of cancer. Most methodologies used to assess the methylation status of a certain gene locus are based on preceding bisulfite conversion of the DNA. Bisulfite treatment of the template DNA leads to deamination of unmethylated cytosines to uracil, leaving only methylated cytosines unaltered (15). Thus, the converted DNA only contains cytosines at positions which were originally methylated.

Amplification of the converted DNA using reverse primers containing guanosines at their 5' end leads to the incorporation of cytosines into the PCR product. These additional cytosines at the 3' end of the PCR product are present in each molecule of the PCR product and therefore 


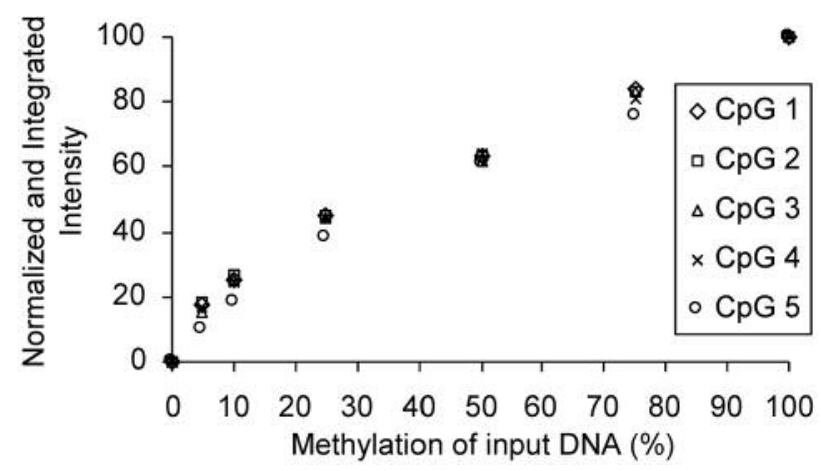

Figure 2. Correlation of normalized peak areas and relative methylation of the template DNA. Normalized peak areas are shown of five single $\mathrm{CpG}$ sites resulting from the sequencing of seven different mixtures of methylated and unmethylated DNA (0, 5, 10, 25, 50, 75 and 100\% methylated DNA). The normalized and integrated intensities are scaled from $0 \%$ to $100 \%$ in order to enable a direct comparison of the five single $C p G$ sites.

behave like completely methylated $\mathrm{CpG}$ sites. Thus, they can be used as an internal reference signal for normalization. Similarly, the incorporation of the normalization signal can also be achieved using modified forward primers containing cytosines at their 5' end and a subsequent sequencing via the reverse primer.

The results of the quantitative bisulfite sequencing method are presented as normalized peak areas. In order to yield the percentage of methylation, these peak areas have to be transformed into the percentage of methylation based on calibration curves. Such calibration curves are prepared applying DNA mixtures with known percentages of methylation. The challenge of preparing suitable calibration mixtures is in the use of DNAs, which are on the one hand completely methylated and completely unmethylated, respectively, and which on the other hand exhibit a symmetric representation of the analyzed locus. MDA DNA is partially single stranded and therefore it is not possible to methylate MDA DNA completely using methyltransferases. However, it is not possible to mix this DNA with completely methylated DNA of natural origin since the loci are not represented symmetrically (16). DNA from sperm bears the potential to be a DNA of natural origin, which should have no major chromosomal rearrangements and has been reported to be unmethylated at many loci (17). Therefore, DNA from sperm and enzymatically methylated equivalents thereof might be suitable for preparing calibration mixtures.

In addition, the usage of a calibration curve allows for a normalization of a PCR bias, i.e. preferred amplification of methylated DNA (18). A PCR bias might result in a deviation from linearity of a response curve as seen in Figure 2.
In this study, it has been shown that the presented method for direct quantitative bisulfite sequencing based on the Sanger method is a simple, affordable and powerful tool for the accurate quantification of methylation of single $\mathrm{CpG}$ sites using standard laboratory equipment, such as capillary electrophoresis instruments.

\section{References}

1 Liu L, Wylie RC, Hansen NJ, Andrews LG and Tollefsbol TO: Profiling DNA methylation by bisulfite genomic sequencing: problems and solutions. Methods Mol Biol 287: 169-179, 2004.

2 Fraga MF and Esteller M: DNA methylation: a profile of methods and applications. Biotechniques 33: 632-649, 2002.

3 Lewin J, Schmitt AO, Adorján P, Hildmann T and Piepenbrock C: Quantitative DNA methylation analysis based on four-dye trace data from direct sequencing of PCR amplificates. Bioinformatics 20: 3005-3012, 2004.

4 Tost J, Dunker J and Gut IG: Analysis and quantification of multiple methylation variable positions in $\mathrm{CpG}$ islands by pyrosequencing. Biotechniques 35: 152-156, 2003.

5 Tost J and Gut IG: DNA methylation analysis by pyrosequencing. Nat Protoc 2: 2265-2275, 2007.

6 Dietrich D, Lesche R, Tetzner R, Krispin M, Dietrich J, Haedicke W, Schuster M and Kristiansen G: Analysis of DNA methylation of multiple genes in microdissected cells from formalin-fixed and paraffin-embedded tissues. J Histochem Cytochem 57: 477-489, 2009.

7 Dean FB, Hosono S, Fang L, Wu X, Faruqi AF, Bray-Ward P, Sun Z, Zong Q, Du Y, Du J, Driscoll M, Song W, Kingsmore SF, Egholm $M$ and Lasken RS: Comprehensive human genome amplification using multiple displacement amplification. Proc Natl Acad Sci USA 99: 5261-5266, 2002.

8 Sailer V, Holmes EE, Gevensleben H, Goltz D, Dröge F, de Vos L, Franzen A, Schröck F, Bootz F, Kristiansen G, Schröck A and Dietrich D: PITX2 and PANCR DNA methylation predicts overall survival in patients with head and neck squamous cell carcinoma. Oncotarget doi: 10.18632/oncotarget.12417.

9 Maier S, Nimmrich I, Koenig T, Eppenberger-Castori S, Bohlmann I, Paradiso A, Spyratos F, Thomssen C, Mueller V, Nährig J, Schittulli F, Kates R, Lesche R, Schwope I, Kluth A, Marx A, Martens JW, Foekens JA, Schmitt M, Harbeck N; European Organisation for Research and Treatment of Cancer (EORTC) PathoBiology group: DNA-methylation of the homeodomain transcription factor PITX2 reliably predicts risk of distant disease recurrence in tamoxifen-treated, node-negative breast cancer patients - Technical and clinical validation in a multi-centre setting in collaboration with the European Organisation for Research and Treatment of Cancer (EORTC) PathoBiology group. Eur J Cancer 43: 1679-1686, 2007.

10 Nimmrich I, Sieuwerts AM, Meijer-van Gelder ME, Schwope I, Bolt-de Vries J, Harbeck N, Koenig T, Hartmann O, Kluth A, Dietrich D, Magdolen V, Portengen H, Look MP, Klijn JG, Lesche R, Schmitt M, Maier S, Foekens JA and Martens JW: DNA hypermethylation of PITX2 is a marker of poor prognosis in untreated lymph node-negative hormone receptor-positive breast cancer patients. Breast Cancer Res Treat 111: 429-437, 2008.

11 Harbeck N, Nimmrich I, Hartmann A, Ross JS, Cufer T, Grützmann R, Kristiansen G, Paradiso A, Hartmann O, 
Margossian A, Martens J, Schwope I, Lukas A, Müller V, MildeLangosch K, Nährig J, Foekens J, Maier S, Schmitt M and Lesche R: Multicenter study using paraffin-embedded tumor tissue testing PITX2 DNA methylation as a marker for outcome prediction in tamoxifen-treated, node-negative breast cancer patients. J Clin Oncol 26: 5036-5042, 2008.

12 Hartmann O, Spyratos F, Harbeck N, Dietrich D, Fassbender A, Schmitt M, Eppenberger-Castori S, Vuaroqueaux V, Lerebours F, Welzel K, Maier S, Plum A, Niemann S, Foekens JA, Lesche $\mathrm{R}$ and Martens JW: DNA methylation markers predict outcome in node-positive, estrogen receptor-positive breast cancer with adjuvant anthracycline-based chemotherapy. Clin Cancer Res 15: 315-323, 2009.

13 Dietrich D, Hasinger O, Liebenberg V, Field JK, Kristiansen G, Soltermann A: DNA methylation of the homeobox genes PITX2 and $S H O X 2$ predicts outcome in non-small-cell lung cancer patients. Diagn Mol Pathol 21: 93-104, 2012.

14 Bañez LL, Sun L, van Leenders GJ, Wheeler TM, Bangma CH, Freedland SJ, Ittmann MM, Lark AL, Madden JF, Hartman A, Weiss G and Castaños-Vélez E: Multicenter clinical validation of PITX2 methylation as a prostate-specific antigen recurrence predictor in patients with post-radical prostatectomy prostate cancer. J Urol 184: 149-56, 2010.

15 Frommer M, McDonald LE, Millar DS, Collis CM, Watt F, Grigg GW, Molloy PL and Paul CL: A genomic sequencing protocol that yields a positive display of 5-methylcytosine residues in individual DNA strands. Proc Natl Acad Sci USA 89: 1827-1831, 1992.
16 Arriola E, Lambros MB, Jones C, Dexter T, Mackay A, Tan DS, Tamber N, Fenwick K, Ashworth A, Dowsett M and Reis-Filho JS: Evaluation of Phi29-based whole-genome amplification for microarray-based comparative genomic hybridisation. Lab Invest 87: 75-83, 2007.

17 Rakyan VK, Down TA, Thorne NP, Flicek P, Kulesha E, Gräf S, Tomazou EM, Bäckdahl L, Johnson N, Herberth M, Howe KL, Jackson DK, Miretti MM, Fiegler H, Marioni JC, Birney E, Hubbard TJ, Carter NP, Tavaré S and Beck S: An integrated resource for genome-wide identification and analysis of human tissue-specific differentially methylated regions (tDMRs). Genome Res 18: 1518-1529, 2008.

18 Warnecke PM, Stirzaker C, Melki JR, Millar DS, Paul CL and Clark SJ: Detection and measurement of PCR bias in quantitative methylation analysis of bisulphite-treated DNA. Nucleic Acids Res 25: 4422-4426, 1997.

Received September 27, 2016

Revised October 13, 2016

Accepted October 14, 2016 